ORIGINAL ARTICLE

\title{
Retired physicians: a survey study by the Turkish Medical Association
}

\author{
Y Gökçe-Kutsal, L Özçakar, Ș Arslan, F Sayek
}

Postgrad Med J 2004;80:101-103. doi: 10.1136/pmi.2003.010215

See end of article for authors' affiliations ....................

Correspondence to: Dr Levent Özçakar, Yeni Ankara sokak 27/1, Cebeci, Ankara, Turkey; lozcakar@yahoo.com

Submitted 19 May 2003 Accepted 17 July 2003
Background: The aim of this study was to assess the quality of life of retired Turkish physicians. The focus was on their working conditions, their health status, and the impact of their disabilities on activities of daily life.

Methods: The survey was conducted using a 35 item questionnaire, which was distributed to the local medical chambers allied with the Turkish Medical Association and thereafter was mailed to retirees aged 65 years and older.

Results: Out of 680 physicians, 391 (57.5\%) responded, and percentages are expressed according to the number of physicians answering each question. The ages of the physicians ranged between 65 years and 91 years with a mean of $72.57 \pm 5.22$ years. Overall, 236 physicians $(60.8 \%)$ were still actively carrying on their profession, and $152(39.2 \%)$ were not. Of the physicians who were working, $0.8 \%$ classified their working conditions as very bad, $9.7 \%$ as unsatisfactory, $37.7 \%$ as satisfactory, $33.6 \%$ as good, and $18.2 \%$ as excellent. The number of physicians with a disability was $42(11.8 \%)$. The number of days on which physicians were hindered in their daily tasks ranged between 0 and 30 days with a mean (SD) of 1.55 (4.88) days, and the amount of sick leave ranged between 0 and 365 days with a mean of 2.25 (21.08) days.

Conclusion: It is believed that planning for retirement in all its aspects should be a legitimate concern of all physicians. Recommendations for future retirees or the construction of guidelines for making this time of life enriching and a period of intellectual growth are awaited.
$\mathrm{F}$ or physicians, retirement is an issue that requires careful contemplation. For some it is rarely considered unless physically mandated, whereas for others it may well be an opportunity to escape from the onerous atmosphere of medical practice. These extremes are reflected in the phrases used to describe this period of life: a doleful prescription for an early demise ${ }^{1}$; final career; the time to grow roses, etc.

There are two important facets of retirement: loss of working status with its financial and psychosocial implications, and ageing with the consequent decreased physical capabilities. The dedicated lifetime pursuit of medical practice makes retirement extremely difficult for physicians, and the giving up of the career that they have devoted their lives to practising, coupled with anxiety about getting older, precipitates sadness, if not sober bereavement. ${ }^{2}$

Though few, there are some studies in the literature describing various aspects of the impact of retirement on physicians' lives. ${ }^{3-7}$ These generally take the form of questionnaires drafted to elicit information and solicit comments and advice from a group of retired physicians. The questions usually ask about their health, life standards, relationships, activities, and finances. The literature shows that personal and spousal health are essential for a "successful" retirement, with other social and financial dimensions being less important.

Consequently we performed a questionnaire study of Turkish retired physicians. Their working and health statuses were examined, and it is the detailed investigation of physicians' disabilities and their impact on daily activities that distinguishes this study from those hitherto reported in the literature.

\section{SUBJECTS AND METHODS}

A survey of Turkish retired physicians was conducted using a 35 item questionnaire, which was distributed to the local medical chambers allied with the Turkish Medical Association and thereafter was mailed to the retirees recorded in their directories, with the prerequisite that recipients must be at least 65 years of age. Forms were sent to 680 physicians, and 391 of them $(57.5 \%)$ responded. Not all questions were answered by all physicians; thus the cited percentages are corrected according to the number of physicians who answered each question.

In addition to 35 general practitioners (9.5\%), the following specialties were represented: internal medicine $(\mathrm{n}=85 ; 25.7 \%)$, ophthalmology $(\mathrm{n}=9 ; 2.7 \%)$, orthopaedics $(\mathrm{n}=9 ; 2.7 \%)$, otorhinolaryngology $(\mathrm{n}=19 ; 5.7 \%)$, paediatrics $(n=40 ; 12.1 \%)$, bacteriology $(n=3 ; 0.9 \%)$, physiology $(\mathrm{n}=3 ; 0.9 \%)$, public health $(\mathrm{n}=3 ; 0.9 \%)$, physical medicine and rehabilitation $(\mathrm{n}=11 ; 3.3 \%)$, radiology $(\mathrm{n}=12 ; 3.6 \%)$, general surgery $(n=37 ; 11.2 \%)$, urology $(n=16 ; 4.8 \%)$, obstetrics and gynaecology $(\mathrm{n}=42 ; 12.7 \%)$, biochemistry $(n=5 ; 1.5 \%)$, dermatology $(n=6 ; 1.8 \%)$, psychiatry $(n=6$; $1.8 \%)$, anaesthesiology $(n=4 ; 1.2 \%)$, chest disease $(n=13$; $3.9 \%$ ), and cardiology, hepatology, pharmacology, microbiology, infectious diseases, gastroenterology, neurosurgery, and plastic and reconstructive surgery $(\mathrm{n}=1 ; 0.3 \%$ each).

The questions were multiple choice and sought data about the physicians' demographic features, medical background, and current medicosocial wellbeing. The questions directed towards medicosocial wellbeing investigated the physicians' active participation in their professions, their physical working conditions, their income and social status, their need for financial support, the presence of any individuals they looked after, the impact of their health status on activities of daily life, their health security and access to medical care, their disabilities, their use of any prostheses, and their expectations.

The statistical analysis was carried out using SPSS 10.0 for Windows. 


\section{RESULTS}

Out of the 391 physicians who returned the questionnaire, 31 (7.9\%) were female and 360 (92.1\%) were male. Their ages ranged between 65 years and 91 years with a mean (SD) of 72.57 (5.22) years. Their marital statuses were as follows: 340 $(87.4 \%)$ were married, $34(8.7 \%)$ were widowed, five $(1.3 \%)$ were divorced, one $(0.3 \%)$ was separated, and nine $(2.3 \%)$ were single.

\section{Working status}

The mean duration of practice was 41.98 (7.20) years and ranged between 22 years and 60 years. In all, 236 (60.8\%) physicians reported that they were still actively carrying on their profession, and $152(39.2 \%)$ were not. The latter group gave the following reasons for not working: retirement $(67.2 \%)$, health related reasons $(21.8 \%)$, and other reasons $(10.9 \%)$. Of those who were not working, $53.3 \%$ declared that they remained in contact with their profession, that is, by following journals or attending meetings; however, $46.7 \%$ denied any type of connection. Of the physicians who were working, $0.8 \%$ classified their working conditions as very bad, $9.7 \%$ as unsatisfactory, $37.7 \%$ as satisfactory, $33.6 \%$ as good, and $18.2 \%$ as excellent.

Overall, $7.8 \%$ of respondents were in need of financial support, but $92.2 \%$ reported that they were financially untroubled and did not require extra support. They rated their income as follows: bad $(\mathrm{n}=39 ; 10.3 \%)$, satisfactory $(\mathrm{n}=203 ; 53.6 \%)$, good $(\mathrm{n}=88 ; 23.2 \%)$, and excellent $(\mathrm{n}=49 ; 12.9 \%)$.

\section{Health status}

One physician $(0.3 \%)$ had private health security; $99.7 \%$ of the physicians had various types of health security provided by the state. In total, $69.9 \%$ had last had a routine check up within the last 12 months, $11.1 \%$ had had one within the last one to two years, $4.5 \%$ within the last two to five years, $5.6 \%$ more than five years ago, 1.4\% could not remember, and $7.5 \%$ had never had a routine check up. The number physicians with some sort of disability was $42(11.8 \%)$. The types and frequencies of disabilities reported are summarised in table 1 , and their impact on the physicians' daily activities are given in table 2. Four physicians were using short leg prostheses, and four other physicians were using long leg prostheses. Twenty physicians $(6.7 \%)$ were using hearing aids, and 258 $(71.3 \%)$ were using either spectacles or contact lenses constantly. The number of days on which disability hindered the physician's daily activities ranged between 0 and 30 days with a mean of 1.55 (4.88) days, and the total amount of sick leave ranged between 0 and 365 days with a mean of 2.25 (21.08) days. Overall, 22 physicians (6.0\%) rated the health services they had been receiving as bad, $134(36.8 \%)$ rated them satisfactory, $119(32.7 \%)$ rated them good, and 89 $(24.5 \%)$ rated them excellent.

Table 1 The disabilities reported

\begin{tabular}{lll}
\hline $\begin{array}{l}\text { Type of } \\
\text { disability }\end{array}$ & $\begin{array}{l}\text { No (\%) of physicians } \\
\text { reporting congenital } \\
\text { disability }\end{array}$ & $\begin{array}{l}\text { No (\%) of physicians } \\
\text { reporting acquired disability }\end{array}$ \\
\hline Orthopaedic & $1(0.3)$ & $17(4.3)$ \\
Neurological & 0 & $12(3.1)$ \\
Psychiatric & 0 & $2(0.5)$ \\
Linguistic & 0 & 0 \\
Visual & 0 & $36(9.2)$ \\
Hearing & 0 & $21(5.4)$
\end{tabular}

Percentages are percentages of the whole group of physicians.

\begin{tabular}{|c|c|c|c|}
\hline \multirow[b]{2}{*}{ Activity } & \multicolumn{3}{|c|}{$\begin{array}{l}\text { Frequency }(\%) \text { with which the } \\
\text { disability interfered with this activity }\end{array}$} \\
\hline & Never & Sometimes & Often \\
\hline Heavy liffing or running & 47.5 & 31.8 & 20.7 \\
\hline $\begin{array}{l}\text { Carrying objects of moderate } \\
\text { weight }\end{array}$ & 64.3 & 26.3 & 9.4 \\
\hline $\begin{array}{l}\text { Climbing the stairs or walking } \\
\text { uphill }\end{array}$ & 57.9 & 31.6 & 10.5 \\
\hline $\begin{array}{l}\text { Bending the trunk forwards and } \\
\text { backwards }\end{array}$ & 69.2 & 23.5 & 7.3 \\
\hline Walking 1-2 km & 70.2 & 17.8 & 12.0 \\
\hline $\begin{array}{l}\text { Eating, dressing, bathing, toilet } \\
\text { activities }\end{array}$ & 87.9 & 6.7 & 5.4 \\
\hline Activities previously enjoyed & 67.0 & 23.9 & 9.1 \\
\hline Home duties & 77.8 & 17.8 & 4.4 \\
\hline Desire to work & 71.4 & 23.2 & 5.4 \\
\hline Effectiveness in daily life & 70.6 & 23.3 & 6.1 \\
\hline Relations with friends & 88.2 & 8.5 & 3.3 \\
\hline
\end{tabular}

\section{DISCUSSION}

Many doctors feel that they are being pushed into a retirement that they do not desire and for which they are ill prepared and poorly suited. They suffer a severe role crisis, equating the loss of practice with a loss of status ${ }^{8}$ or with the loss of their self image as a healer. ${ }^{3}$ On the other hand, physicians who have made financial provision, who want to reduce work related pressure and increase leisure time, and who anticipate healthy retirement, or those who are dissatisfied with their jobs, intend to retire early. ${ }^{5}$ It is noteworthy that in our population $67.2 \%$ of the physicians who were not working declared that they had stopped because they were "retired". We think that this implies that the ideas of being "exhausted" and "in need of some rest from now on" also play a part in the decision to retire.

Rowe observed that, among physicians who found retirement better than expected, four out of five advocated a separation from medicine. ${ }^{4}$ On the other hand, among those whose retirement was about the same as they had expected, three out of four advised remaining involved in medicine, and all the physicians whose retirement was not as good as they had expected recommended staying current in medicine. The majority of our retirees continued working as doctors, and the working conditions seemed to gratify them both psychosocially and financially. Accordingly, we think that to advise retiring doctors to preserve a foothold in medicine would not be unfounded.

Nearly all the physicians were supported by the state and thus had no problems related to health expenditure. Together with the reasonable increase in health awareness among physicians that is expected, the fact that $81 \%$ had had a routine check up within the last two years indicates that physicians have easy access to health care. The physicians themselves agreed with this, since the great majority were happy with the services. On the other hand, the fact that $7.5 \%$ of physicians had never had a check up cannot be rationalised unless they were all perfectly well. Among the disabilities reported, ophthalmological problems were the most common, followed by hearing, orthopaedic and neurological problems, respectively (table 1), which is in accordance with the normal elderly population. In a similar study of Norwegian physicians, the most prevalent complaint was found to be lower back trouble, followed by arthrosis and hypertension. ${ }^{9}$

Disability among the elderly, particularly those who are physically frail, is a highly dynamic process with considerable 
diversity, which may be reversible and is often recurrent. ${ }^{10}$ In terms of self rated health, the most important activities of daily living are those involving mobility, and the effect of problems in performing each activity of daily living depends on the functional capacity of the individual. ${ }^{11}$ Therefore our questions about the impact of disability on daily life were oriented accordingly. It is clear that the most obvious decline in daily activities was in the group of activities that require muscle strength. While few retirees had problems with distance walking and carrying objects, running and lifting heavy objects could not be performed comfortably. Nonetheless, these activities are not necessary (in fact they can be dangerous) for the elderly. It is fortunate that the activities that are biological necessities did not seem to be significantly hindered. Nor was there a major constraint on social relations. Here it is pertinent to underscore another mainstay of successful retirement, which is a good spouse. A spouse may be able to replace the support network previously provided by staff, patients, or other colleagues. It has been reported that the relationship with a spouse improves as the amount of time spent at home increases. ${ }^{12}$

To summarise, the prime ingredients of a successful retirement are good health and happy spousal and social relationships. We believe that planning for retirement in all its aspects should be a legitimate concern of all physicians, since it would be a tragedy to arrive at retirement with no financial security and with no realistic plans for maintaining intellectual, physical, cultural, and social wellbeing. Recommendations to future retirees and the construction of guidelines for making this time of life enriching and a period of intellectual growth are awaited. The lists of hobbies are without number, and there are endless vistas for retired physicians to explore.

\section{ACKNOWLEDGEMENTS}

The authors thank the members of the Executive Committee of the Turkish Medical Association and the executives of the local chambers for gathering the data and for their cooperation during this study.

\section{Authors' affiliations}

Y Gökçe-Kutsal, L Özçakar, Department of Physical Medicine and Rehabilitation, Hacettepe University Medical School, Ankara, Turkey

S.Arslan, Department of Physical Medicine and Rehabilitation,

Gaziosmanpassa University Medical School, Tokat, Turkey

F Sayek, President, Turkish Medical Association, Ankara, Turkey

\section{REFERENCES}

1 Hoser RH. The final career. West J Med 1993;158:196-7.

2 Weisman AD. The physician in retirement: transition and opportunity. Psychiatry 1996;59:298-306.

3 Virshup B, Coombs RH. Physicians' adjustment to retirement. West J Med 1993; 158: 142-4.

4 Rowe ML. Health, income, and activities of retired physicians. NY State J Med 1989;89:450-3.

5 Davidson JM, Lambert TW, Parkhouse J, et al. Retirement intentions of doctors who qualified in the United Kingdom in 1974: postal questionnaire survey. $J$ Public Health Med 2001;23:323-8.

6 Lees $\mathbf{E}$, Liss SE, Cohen IM, et al. Emotional impact of retirement on physicians. Tex Med 2001;97:66-71.

7 Seim HC, Mitchell JE. Life after medical practice. A retirement profile of Minnesota physicians. Minn Med 1995;78:27-30.

8 Perry WJ. A physician's prologue to retirement. Postgrad Med 1984;76:81-3.

9 Gogstad A, Aasland OG. [How are the retired physicians?] Tidsskr Nor Laegeforen 1998;1 18:1378-82. (In Norwegian.)

10 Gill TM, Kurland B. The burden and patterns of disability in activities of daily living among community-living older persons. J Gerontol Med Sci 2003:58A:70-5

11 Gama EV, Damian J, del Molino JP, et al. Association of individual activities of daily living with self-rated health in older people. Age Ageing 2000;29:267-70

12 Liss SE, Cohen IM, Charalampous KD. Insights into physician retirement. Tex Med 2001;97:72-4. 